\title{
Population structure of an arborescent aloe (Aloe marlothii) in Botswana
}

\author{
Jonathan H. Titus ${ }^{1 *}$, Priscilla J. Titus ${ }^{1}$, Melinda Laituri ${ }^{2}$ and Bongani Sethebe ${ }^{3}$ \\ ${ }^{1}$ Department of Biological Sciences, Fredonia, Fredonia, NY 14063, USA. \\ ${ }^{2}$ Warner College of Natural Resources, Colorado State University, 101 Natural Resources Building Campus Delivery \\ 1401, Fort Collins, CO 80523-1401, USA. \\ ${ }^{3}$ Department of Biological Sciences, University of Botswana, Gaborone, Botswana.
}

Accepted 24 May, 2012

\begin{abstract}
Aloe marlothii A. Berger (Asphodelaceae) (ALMA), an arborescent CAM succulent, were measured in two populations of historical significance near Molepolole, Botswana with the objective of determining size class distribution and therefore assess future population viability. It was found that plant height and a variety of other plant attributes were strongly correlated, including being reproductive and number of capsules. The most common size class was seedlings for one population, and 11 to $50 \mathrm{~cm}$ size class for the other population. There were more individuals in the 101 to $200 \mathrm{~cm}$ size class than in some of the small size classes indicating a potential population decline. Seedlings were very patchy in distribution and the majority of ALMA, both seedlings and smaller mature individuals, were found under nurse plants. Seed production was high and seed viability averaged $62 \%$. In a third population in the Mokolodi Nature Preserve, individuals were all $>4.5 \mathrm{~m}$ in height and were sparsely distributed. It was concluded that the Molepolole populations appear to be stable but that steps should be taken to establish long-term monitoring and protect the Molepolole populations. The Mokolodi population appears to be at risk.
\end{abstract}

Key words: Aloe, Botswana, succulent, conservation, demography, seedlings.

\section{INTRODUCTION}

Aloe marlothii A. Berger (Asphodelaceae) (ALMA), is an arborescent CAM succulent that is widespread in the northern and north-eastern summer rainfall region of South Africa and adjacent Botswana. ALMA is usually less than $6 \mathrm{~m}$ in height but occasionally reaches up to 10 $\mathrm{m}$ in height. It occurs in large numbers as a dominant and conspicuous plant often on rocky terrain. The inflorescence is a branched panicle of up to 50 vertical to horizontal racemes, with showy orange or red flowers varying in shape and colour across the geographical range of the species (Van Wyk and Smith, 2005; Kew, 2011). ALMA has typical bird pollinated flowers that, when flowering during the dry winter months (June to September), provide copious amounts of nectar for a

\footnotetext{
*Corresponding author. E-mail: titus@fredonia.edu.
}

wide variety of bird species. For example, 42 bird species utilized ALMA nectar at a site in South Africa (Symes and Nicolson, 2008; Symes et al., 2009). Thus, ALMA may be a keystone species by supplying perches and nesting sites for birds, nectar for pollinating birds, and food, habitat and moisture for many animals as do other Aloes (Midgley et al., 1997). ALMA is rated by the International Union for Conservation of Nature (IUCN) as a species of least concern in South Africa (Kew, 2011) due to the fact that the species appears to be doing well across its South African range. Its status in Botswana is unranked due to lack of data. ALMA is listed in CITES in Appendix II of Newton (2001). Appendix II of Newton (2001) lists species that are not necessarily now threatened with extinction but that may become so unless trade is closely controlled.

ALMA plays a pivotal role in Botswana history (Campbell and Main, 2003). In the 1850s, the Boers 
(Dutch-speaking white people from South Africa) were trying to establish a state encompassing part of presentday Botswana. By 1852, the Boers were pushing into the area that was then and is currently the large village of Molepolole. At the time the inhabitants of Molepolole were the Bakwena, whom were viewed as potential slaves by the Boers and therefore fiercely resisted the Boer advance. A legend states that a nocturnal invading Boer force saw the large stands of ALMA (Mogwapha in Bakwena) in Molepolole and in the darkness mistook the ALMA for fierce Bakwena warriors and fled in terror (Campbell and Main, 2003). According to legend, because of ALMA the Boers were unsuccessful in conquering the area and retreated southward.

ALMA has a myriad of ethnomedicinal uses. For example, leaf exudates are used as a weaning aid and a purgative and there is a leaf preparation for intestinal parasites. Ethnoveterinary uses include a treatment for African horse sickness and internal and external parasites in livestock. In addition, the prickly leaves are used to scrape animal hides (Grace et al., 2008, 2009).

In harsh arid environments, the survival of many succulent species is precarious because of adult mortality, infrequent seedling recruitment and because populations are generally small and sparse. Slight decreases in seedling recruitment rates or increases in adult mortality can endanger populations. Succulent recruitment is episodic because of the rarity of suitable climatic events, that is, periods of sufficient precipitation combined with appropriate temperatures. These variations in climate strongly influence regeneration patterns in a variety of arborescent succulent species (Jordan and Nobel, 1979, 1982; Pierson and Turner, 1998; Titus, 2004; Drezner, 2006; Duncan et al., 2006). These large arid-zone succulents are relatively long-lived species, which allows plant populations to survive for many decades without recruitment before local extinction.

In order to study the population structure of arborescent succulents, a direct relationship between size and age has been inferred. Long-term data sets have supported this size-age inference although growth rates generally decline as species reach a certain height (Pierson and Turner, 1998; Duncan et al., 2006) and the relationship improves when summer rainfall patterns are included (Drezner, 2003, 2006).

The majority of research on arborescent succulents has been conducted in arid areas. Data is lacking for arborescent succulents such as $A$. marlothii that grow in semi-arid environments. Semi-arid environments are characterized by both annual precipitations up to $70 \mathrm{~cm}$, that is, only slightly below potential evapotranspiration, and a much lower inter-annual rainfall variation of 20 to $50 \%$ compared to arid zone inter-annual rainfall variation of 50 to $100 \%$ (IISD, 2011). Thus, regeneration events are less likely to be as episodic in semi-arid environments as they are in arid areas.

Demographic factors are little known for ALMA, therefore, in this study we have made inferences based solely on size class information. Like other Aloes, ALMA grows from a terminal apex which implies a rough correlation between height and age. In this study, we have assessed the size distribution and other attributes of individuals in three populations and from this data we have made inferences about the future status of these populations.

\section{METHODOLOGY}

This study was conducted at two sites near the town of Molepolole (1217 m asl) located $50 \mathrm{~km}$ west of Gaborone the capital of Botswana (Figure 1). Molepolole has a hot semi-arid climate with precipitation being sparse and variable with most of the rainfall occurring in the summer months between October and April. In Gaborone, mean annual precipitation is $44.4 \mathrm{~cm}$ and mean temperature is $22^{\circ} \mathrm{C}$ ranging from a mean minimum of $4^{\circ} \mathrm{C}$ in July to a mean maximum of $33^{\circ} \mathrm{C}$ in December and January (World Weather Online, 2011). The "Prison site" is located northwest of Molepolole along the Khutse highway. It is a narrow strip east of the highway and west of fenced cattle posts and is approximately 200

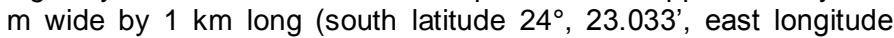
$\left.25^{\circ} 28.309^{\prime}\right)$. The Molepolole Prison is located just beyond the southern end. The "School site" is located west of the town near a secondary school and occupies an area of approximately 500 by $500 \mathrm{~m}$ (south latitude $24^{\circ}, 23.035^{\prime}$, east longitude $25^{\circ}, 29.304^{\prime}$ ). Both areas experience heavy grazing by cattle and goats and pedestrian traffic and woodcutting with plenty of evidence of these activities. No baboons were observed at either site during the course of the study at Molepolole.

Eleven $100 \mathrm{~m}^{2}$ square plots, chosen to represent the range of densities and conditions of ALMA, were surveyed at each site. In each plot the cover of each species was estimated. Because this survey occurred during the dry season, herbaceous species were unidentifiable and total grass and forb cover were estimated.

Each ALMA in the plots was measured for total height, meristem height (height to the base of the leaves), trunk diameter $10 \mathrm{~cm}$ above the ground surface, and total number of leaves. Canopy length is the total height minus the length of the stem (meristem height). In addition, the longest leaf rosette diameter and the diameter at $90^{\circ}$ to that were measured. The rosette area was then calculated as the area of an ellipse $\left(\mathrm{a} / 2^{*} \mathrm{~b} / 2^{*} \mathrm{pi}\right)$. Plant health was subjectively estimated - good (all the leaves except the lowest outside rosette have green tips and plant appears healthy), medium (some of the leaves above the lowest rosette have black tips or other damage and the plant appears less healthy), and poor (very few live leaves and the plant appears to be declining). If reproductive, the number of inflorescence branches and capsules were counted.

For each ALMA $>5 \mathrm{~cm}$ in height, the distance to the nearest neighbor $>5 \mathrm{~cm}$ in height was recorded. The distance to a seedling was not used because seedling mortality is most likely high and does not represent the distribution of ALMA over the long-term. In any case, because seedling distribution was very patchy (most of the seedlings occurred in just a few patches) whether or not nearest neighbor distances included seedlings or not would have a negligible effect on overall mean nearest neighbor distances. For seedlings, the distance to the nearest ALMA of any size class was recorded. Many ALMA in this area have a nurse plant, that is, they are growing underneath the canopy of one, two or three shrubs or trees. The nurse species were identified. In addition, any other attributes of the ALMA, such as angle of leaning, presence of a termite mound at the base, etc., were noted. The mentioned characteristics that were still measurable were assessed on dead ALMA. Dead ALMA that were too decomposed for any features to be measured were simply counted. 


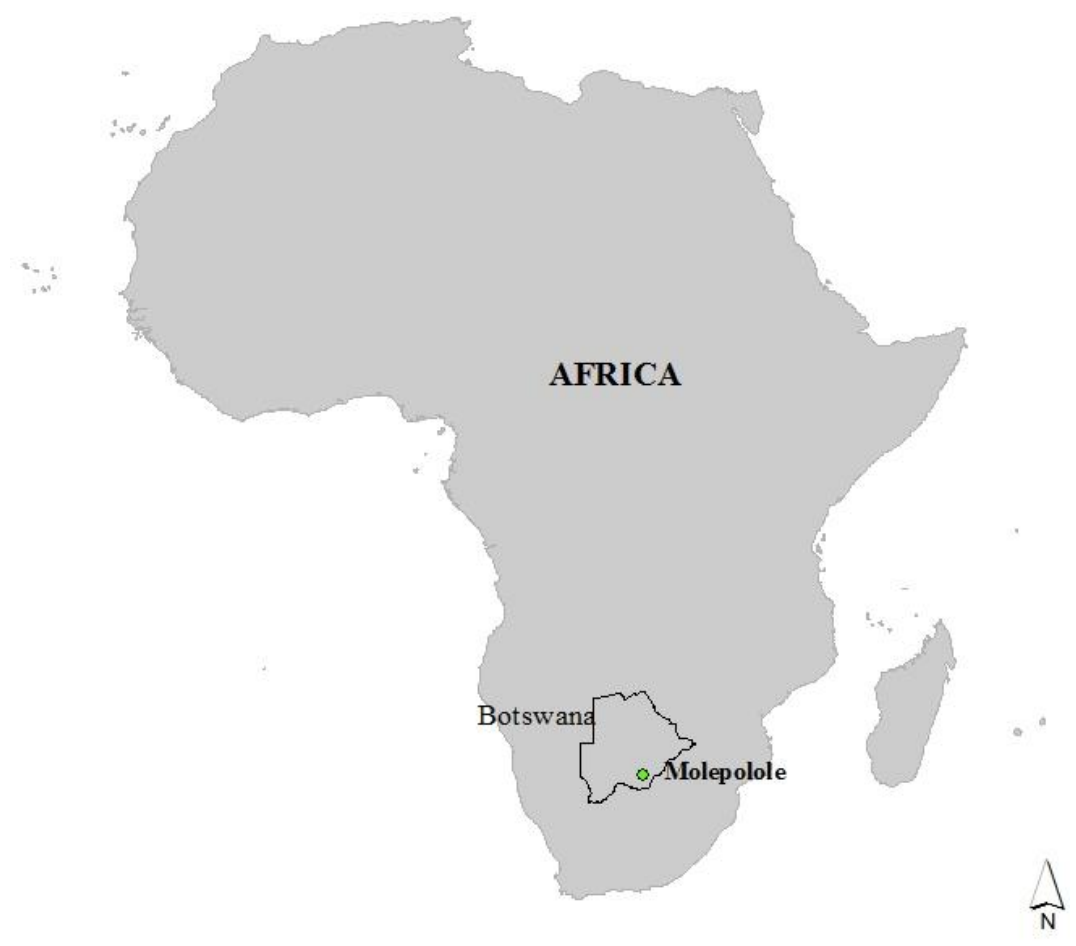

Figure 1. Map of Africa showing the location of Botswana and Molepolole.

Because plots were chosen subjectively in order to obtain a more accurate estimate of ALMA density in each population, a corresponding transect $500 \mathrm{~m}$ long and $2 \mathrm{~m}$ wide $\left(1000 \mathrm{~m}^{2}\right.$ in area) was surveyed in each site. This allowed a comparison of ALMA density obtained in the plots versus in a transect that cut across each site.

In order to compare ALMA size structure in a different location with the Molepolole sites, an assessment of ALMA size structure was conducted at the Mokolodi Nature Reserve (S24 ${ }^{\circ} 44.342^{\prime}$, E25 $\left.5^{\circ} 48.937^{\prime}\right) 15 \mathrm{~km}$ south of Gaborone and $60 \mathrm{~km}$ southeast of Molepolole on 8 June, 2011. This population consists of sparsely distributed ALMA plants. In the southern portion of the Reserve, $\sim 20 \mathrm{~km}$ of roads were driven and every ALMA observed was measured as previously described. A minimum of $400 \mathrm{~m}^{2}$ area around every ALMA observed was extensively searched for smaller size classes. The vegetation in Mokolodi is similar to that of Molepolole, however, domestic stock grazing has been excluded from the Reserve since 1994 and wild ungulates and baboons abound.

On 12 November, 2010, 10 capsules were collected from each of 12 ALMA at the Prison site. The number of seeds in each capsule was counted. On 8 February, 2011, 25 seeds from each of these 12 ALMA plants were planted in flats in the University of Botswana greenhouse. The seeds of each plant were planted in one half of six $50 \mathrm{~cm}$ by $25 \mathrm{~cm}$ flats with a depth of $20 \mathrm{~cm}$. Substrate was $\sim 90 \%$ potting soil and $5 \%$ each of sand and vermiculite. The greenhouse used natural lighting and temperature. Flats were watered with tap water three times a week. Seedlings were counted every 2 weeks after germination commenced for 3 months.

\section{Analysis}

ALMA total height, meristem height, trunk diameter, number of leaves, distance from the base of the leaves to the top of the leaves (leaf canopy height), percent of total height occupied by the
Canopy (\% canopy), canopy area and nearest non-seedling neighbor distance were tested for correlation by Spearman's rank correlation coefficient. A non-parametric test was utilized because many data sets were strongly non-normal. Spearman's rank correlation coefficient was also conducted on the ALMA $>10 \mathrm{~cm}$ in height to determine if some of the correlations found were influenced by the seedlings and small saplings and not by the larger individuals.

\section{RESULTS}

A total of 873 live ALMA were measured at the Prison site and 518 live ALMA were measured at the School site. The size distribution was quite different between the two sites with about half of the ALMA being seedlings below $2 \mathrm{~cm}$ in height at the Prison site compared to $11 \%$ at the School site (Figure 2). ALMA in the 11 to $50 \mathrm{~cm}$ range was much more common at the School site than at the Prison site.

The tallest ALMAs were $415 \mathrm{~cm}$ at the Prison site and $480 \mathrm{~cm}$ at the School site (Table 1). Meristem height ranged from $0 \mathrm{~cm}$ for seedlings to $430 \mathrm{~cm}$ for the largest ALMA. Leaf canopy height ranged from $0.1 \mathrm{~cm}$ for the smallest seedlings to $110 \mathrm{~cm}$, and averaged ( $\pm \mathrm{sd}$ ) $68.2 \pm$ $28.4 \%$ of the total height of an ALMA. Trunk diameter ranged from $0.1 \mathrm{~cm}$ for seedlings to $26 \mathrm{~cm}$ for large ALMA. Number of leaves ranged from 1 leaf in seedlings to 33 leaves in large ALMA. The area of the canopy ranged from 0.04 to $30,332 \mathrm{~cm}^{2}$. There were $64(12.4 \%)$ reproductive individuals at the Prison site and 48 (5.5\%) 

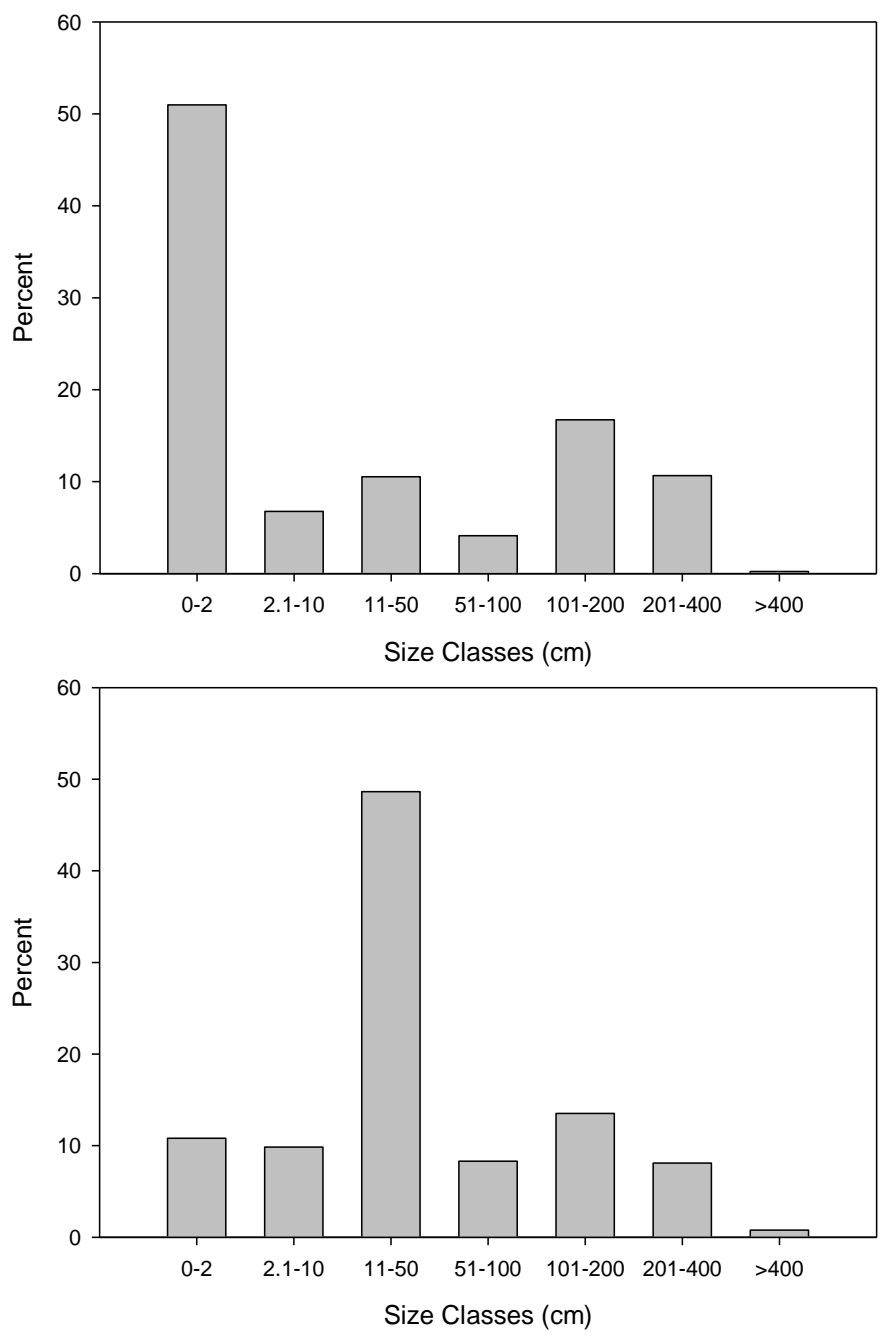

Figure 2. Size class distribution of $A$. marlothii in Molepolole, Botswana in 11 to $100 \mathrm{~m}^{2}$ plots at the Prison site (upper) and the School site (lower).

at the School site. The shortest reproductive individual was $155 \mathrm{~cm}$ tall (Table 1 ).

The characteristics measured on ALMA plants, that is, total height, meristem height, trunk diameter, leaf canopy length, \%canopy length, leaf number, canopy area, nearest neighbor and presence of reproductive structures (bearing an infructescence) were all highly correlated with $p<0.001$ in all cases (Table 2). Correlations were all positive, as would be expected, except for \%canopy length which was a negative correlation indicating that as the ALMA got taller the percentage of the stem occupied by the leaves became a small percentage of the total height. As ALMA increased in height, nearest neighbor distance increased. If the two sites are analyzed separately all correlations remain significant with a pvalue $<0.001$, thus, the two sites were combined for these analyses. If only the 832 ALMA $>10 \mathrm{~cm}$ in height are tested for correlations (excluding seedlings and small saplings) all of the features remain highly correlated with $p<0.001$ in all cases (not shown).

Amongst reproductive individuals, canopy area had the strongest correlation with number of inflorescence branches and number of capsules (Table 3). Number of leaves, trunk diameter, and total height were generally correlated with reproductive effort but not in all cases. Canopy length was strongly correlated with reproductive effort at the Prison site but not at the School site. Although reproductive ALMA characteristics differed little between the two sites; correlations are shown separately because of the differences that did occur (Table 3).

The nearest neighbor distance between ALMA ranged from $0.1 \mathrm{~cm}$ for clustered seedlings to $500 \mathrm{~cm}$ (Table 1). The mean \pm sd nearest neighbor distance, including the distance of seedlings from other seedlings, was $32 \pm 54$ $\mathrm{cm}$ at the Prison site and $52 \pm$ at the School site. However, for ALMA $>5 \mathrm{~cm}$ in height the nearest neighbor distance between the two sites became similar ( $57 \pm 68$ $\mathrm{cm}$ at the Prison site and $54 \pm 67 \mathrm{~cm}$ at the School site). The large number of clustered seedlings at the Prison site caused the overall nearest neighbor distance to be considerably smaller when seedlings are included (Table 4).

Seedlings were highly clustered as seen by the majority of the seedlings only occurring in one plot at each site, that is, $85 \%$ of the seedlings at the Prison site and $62 \%$ at the School site, occurred in just one plot (Table 4). In these plots, the vast majority of the seedlings occurred under just a few nurse plant species, particularly Acacia tortilis, Boscia foetida, Euclea undulata, and Grewia flava at the Prison site and $A$. tortilis and E. undulata at the School site (Table 5).

The vast majority of ALMA were under one or more nurse plants at both sites (Tables 5 and 6). For seedlings 0 to $2 \mathrm{~cm}$ tall, 99.8 and $100 \%$ were under a nurse plant at the Prison site and School site, respectively. This slowly declined with increasing size but most ALMAs were still under nurse plants in the 51 to $100 \mathrm{~cm}$ tall size class. The percentage drops sharply for ALMA 101 to $200 \mathrm{~cm}$ tall. ALMA $>200 \mathrm{~cm}$ in height did not have nurse plants. This is most likely due to either the disappearance of the nurse plant due to age and/or competition or simply that the ALMA is taller than the nurse. At the Prison site, $6.2 \%$ and at the School site $18.8 \%$ of the ALMA with nurses were under 2 or 3 nurse plants. At the Prison site there were 9 different nurse plant species with $B$. foetida and $E$. undulata being the most common and at the School site there were 18 different nurse plant species with $E$. undulata and $A$. marlothii being the most common (Table $6)$.

Dead ALMAs were not common at either sites (47 dead ALMA versus 1391 live ALMA) and no standing dead ALMA were observed (Table 7). Dead ALMA represented a range of size classes except for the smallest size classes, which would be difficult to detect. There were more dead ALMA at the School site (34) than at the Prison site (13) but the dead ALMA had greater height, 
Table 1. Mean \pm standard deviation and range for characteristics of all ALMA and the reproductive ALMA at two sites near Molepolole, Botswana.

\begin{tabular}{lcccc}
\hline \multirow{2}{*}{ ALMA characteristic } & \multicolumn{2}{c}{ Prison } & \multicolumn{2}{c}{ School } \\
\cline { 2 - 5 } & Mean \pm sd & Range & Mean \pm sd & Range \\
\hline Total A. marlothii & & & & \\
Total height $(\mathrm{cm})$ & $60 \pm 88$ & $0.1-415$ & $65 \pm 86$ & $0.1-480$ \\
Meristem height $(\mathrm{cm})$ & $40 \pm 64$ & $0-480$ & $39 \pm 63$ & $0-430$ \\
Trunk diameter $(\mathrm{cm})$ & $3.6 \pm 4.8$ & $0.1-26$ & $4.9 \pm 5.2$ & $0.1-26$ \\
Number leaves & $6.8 \pm 2.8$ & $1-32$ & $8.1 \pm 7.5$ & $1-33$ \\
Canopy length $(\mathrm{cm})$ & $20 \pm 26$ & $0.1-110$ & $26 \pm 26$ & $0.1-110$ \\
\% Canopy length & $72 \pm 31$ & $8-100$ & $61 \pm 22$ & $8-100$ \\
Canopy area $\left(\mathrm{cm}^{2}\right)$ & $2199 \pm 4662$ & $0.04-27883$ & $2704 \pm 5450$ & $0.20-30332$ \\
Nearest neighbor & $32 \pm 54$ & $1-500$ & $52 \pm 64$ & $1-440$ \\
NN ALMA $>5 \mathrm{~cm}$ height & $57 \pm 68$ & $3-500$ & $54 \pm 67$ & $2-440$ \\
& & & & \\
Reproductive & & & & \\
Number inflorescence branches & $9.8 \pm 5.6$ & $1-28$ & $8.8 \pm 3.4$ & $1-17$ \\
Number capsules & $238 \pm 165$ & $0-800$ & $184 \pm 100$ & $0-440$ \\
Total height $(\mathrm{cm})$ & $236 \pm 59$ & $155-415$ & $234 \pm 59$ & $160-410$ \\
Meristem height $(\mathrm{cm})$ & $162 \pm 55$ & $85-340$ & $159 \pm 58$ & $88-330$ \\
Trunk diameter $(\mathrm{cm})$ & $13.5 \pm 3.6$ & $8-23$ & $14.7 \pm 3.5$ & $9-26$ \\
Number leaves & $23.5 \pm 2.8$ & $16-28$ & $22.5 \pm 4.2$ & $15-33$ \\
Canopy length $(\mathrm{cm})$ & $74 \pm 11$ & $50-100$ & $75 \pm 14$ & $30-110$ \\
$\%$ Canopy length & $33 \pm 6$ & $16-45$ & $34 \pm 8$ & $18-45$ \\
Canopy area $\left(\mathrm{cm}{ }^{2}\right)$ & $14137 \pm 5633$ & $3356-27883$ & $14413 \pm 4420$ & $3297-30332$ \\
Nearest neighbor & $107 \pm 118$ & $13-500$ & $109 \pm 91$ & $7-330$ \\
\hline A & & &
\end{tabular}

A total of 873 ALMA were measured at the Prison site and 518 at the School site and 48 reproductive ALMA were measured at the Prison site and 64 at the School site. NN ALMA $>5 \mathrm{~cm}$ height is the nearest neighbor distances for ALMA $>5 \mathrm{~cm}$ in height.

Table 2. Spearman's correlation coefficients between structures of 1391 ALMA plants measured at two sites near Molepolole, Botswana.

\begin{tabular}{lcccccccc}
\hline ALMA characteristic & Reproductive & $\begin{array}{c}\text { Nearest } \\
\text { neighbor }\end{array}$ & $\begin{array}{c}\text { Canopy } \\
\text { area }\end{array}$ & $\begin{array}{c}\text { \% Canopy } \\
\text { length }\end{array}$ & $\begin{array}{c}\text { Canopy } \\
\text { length }\end{array}$ & $\begin{array}{c}\text { Number of } \\
\text { Leaves }\end{array}$ & $\begin{array}{c}\text { Trunk } \\
\text { diameter }\end{array}$ & $\begin{array}{c}\text { Meristem } \\
\text { height }\end{array}$ \\
\hline Total height & 0.432 & 0.740 & 0.962 & -0.925 & 0.987 & 0.907 & 0.926 & 0.974 \\
Meristem height & 0.431 & 0.752 & 0.970 & -0.969 & 0.948 & 0.907 & 0.942 & \\
Trunk diameter & 0.440 & 0.747 & 0.938 & -0.898 & 0.910 & 0.855 & & \\
Number of leaves & 0.447 & 0.707 & 0.933 & -0.838 & 0.916 & & & \\
Canopy length & 0.442 & 0.735 & 0.961 & -0.874 & & & & \\
\% Canopy length & -0.359 & -0.716 & -0.915 & & & & & \\
Canopy area & 0.453 & 0.762 & & & & & & \\
Nearest neighbor & 0.315 & & & & & & & \\
\hline
\end{tabular}

Canopy length is the length of the stem occupied by leaves. Percent canopy length is the percent of total height that is composed of leaves. Nearest neighbor is the distance of an ALMA to its nearest non-seedling conspecific. All of the correlations are significant at $p<0.001$.

trunk diameter and nearest neighbor distance at the Prison site than at the School site. At the School site $85.3 \%$ of the dead ALMAs were under nurse plants whereas at the Prison site $23.1 \%$ of the dead ALMAs were under nurse plants. This may be partially due to the larger dead ALMA at the Prison site - large ALMA was less likely to have a nurse. A smaller percentage of dead ALMAs were under nurse plants than live ALMA. 
Table 3. Spearman's correlation coefficients and p-values between structures of reproductive ALMA at two sites near Molepolole, Botswana.

\begin{tabular}{lcccccccc}
\hline \multirow{2}{*}{$\begin{array}{l}\text { ALMA } \\
\text { characteristic }\end{array}$} & \multicolumn{4}{c}{ Prison site } & \multicolumn{4}{c}{ School site } \\
\cline { 2 - 10 } & $\begin{array}{c}\text { Number inflorescence } \\
\text { branches }\end{array}$ & \multicolumn{2}{c}{ Number capsules } & $\begin{array}{c}\text { Number inflorescence } \\
\text { branches }\end{array}$ & \multicolumn{2}{c}{ Number Capsules } \\
\cline { 2 - 10 } & $\boldsymbol{r}$ & $\boldsymbol{p}$ & $\boldsymbol{r}$ & $\boldsymbol{p}$ & $\boldsymbol{r}$ & $\boldsymbol{p}$ & $\boldsymbol{r}$ & $\boldsymbol{p}$ \\
\hline Total height & 0.297 & 0.041 & 0.281 & 0.053 & 0.214 & 0.089 & 0.300 & 0.016 \\
Meristem height & 0.229 & 0.118 & 0.222 & 0.129 & 0.210 & 0.096 & 0.257 & 0.040 \\
Trunk diameter & 0.264 & 0.070 & 0.331 & 0.021 & 0.280 & 0.025 & 0.295 & 0.018 \\
Number of leaves & 0.401 & 0.005 & 0.426 & 0.003 & 0.223 & 0.077 & 0.264 & 0.035 \\
Canopy length & 0.462 & 0.001 & 0.479 & 0.001 & 0.046 & 0.721 & 0.125 & 0.327 \\
\% Canopy length & 0.048 & 0.748 & 0.021 & 0.887 & -0.157 & 0.215 & -0.148 & 0.242 \\
Canopy area & 0.581 & $<0.000$ & 0.651 & $<0.001$ & 0.343 & 0.006 & 0.527 & 0.000 \\
Nearest neighbor & 0.114 & 0.442 & 0.590 & 0.691 & -0.104 & 0.415 & -0.226 & 0.072 \\
Number capsules & 0.831 & $<0.000$ & & & 0.562 & 0.000 & & \\
\hline
\end{tabular}

Forty-eight reproductive ALMA were measured at the Prison site and 64 at the School site.

Table 4. Percent ALMA seedlings $(\leq 5 \mathrm{~cm}$ tall) that occurred in each of the plots at the Prison and School sites near Molepolole, Botswana.

\begin{tabular}{ccc}
\hline \multirow{2}{*}{ Plot number } & Prison & School \\
\cline { 2 - 3 } & Site percent & Site percent \\
\hline 1 & 0 & 16.2 \\
2 & 0.4 & 7.4 \\
3 & 0 & 1.5 \\
4 & 0 & 1.5 \\
5 & 85.0 & 0 \\
6 & 1.4 & 1.5 \\
7 & 0.2 & 0 \\
8 & 0.4 & 0 \\
9 & 12.6 & 1.5 \\
10 & 0 & 8.8 \\
11 & 0 & 61.8 \\
\hline
\end{tabular}

The total number of seedlings was 492 seedlings at the Prison site and 68 seedlings at the School site.

The transect across each site sampled $1000 \mathrm{~m}^{2}$ and yielded an ALMA density of $65.4 / 100 \mathrm{~m}^{2}$ at the Prison site and $33.7 / 100 \mathrm{~m}^{2}$ at the School site (Table 8). The 2 to 10 $\mathrm{cm}$ size class and 11 to $50 \mathrm{~cm}$ size class were most common at the Prison site and School site, respectively. At the Prison site, $7.8 \%$ of the ALMAs were reproductive and at the School site $4.5 \%$ were reproductive. Total ALMA density in the plots was higher than in the transects. This can be attributed to, in part, the patchiness of the seedling stage and the likelihood that a transect would miss these patches.

At Mokolodi Game Reserve, only 14 ALMA were observed along $20 \mathrm{~km}$ of road. All of these ALMA were quite tall (mean \pm sd $5.8 \pm 1.1 \mathrm{~m}$; range 4.5 to $7.5 \mathrm{~m}$ ) with a large number of leaves (mean \pm sd $59 \pm 18$ leaves). No smaller size classes were detected even though the landscape is quite open and ALMA are easy to detect.

In the 120 capsules sampled from 10 ALMA, the number of seeds per capsule was $85 \pm 22$ (mean \pm sd) with a range of 32 to 135 . For each ALMA, the mean number of seeds per capsule ranged from 63 to 113. In the greenhouse, ALMA seeds began germinating after 11 days. By 14 days, $41 \%$ of the seeds that were to germinate had germinated and germination was completed within 1 month with a mean \pm sd germination of 62 $\pm 16 \%$. Over the next 2 months, $87 \%$ of these seedlings survived.

Out of the 120 capsules sampled 5 ( 1 from one ALMA and 4 from another ALMA) had insect damage. However, the insect damage did not appear to reduce seed numbers. In $\sim 9 \%$ of the reproductive ALMA one or more of the inflorescence branches had a borehole at the base. During the study the insects were not detected. The effect of this insect attack was that no capsules matured on branches with a borehole. Because the number of infestations was low this did not appear to have any appreciable effect on seed production.

\section{DISCUSSION}

The two populations differ in their size distributions with the Prison site having a considerable number of seedlings and the School site having many juvenile individuals in the 11 to $50 \mathrm{~cm}$ size class (Figure 2). The majority of the seedlings occur in just a few dense patches, particularly at the Prison site (Table 4). The 2 years prior to this study in Botswana have been wetter than usual; before that Botswana experienced a decade long drought. Thus, the large number of seedlings may reflect recent moist conditions beneficial for recruitment.

Seedling mortality is unknown but is presumably high 
Table 5. Numbers and percentages of ALMA in five size classes with one or more nurse plant at two sites near Molepolole, Botswana.

\begin{tabular}{ccccc}
\hline \multirow{2}{*}{ A. marlothii size class $\mathbf{( c m )})$} & \multicolumn{2}{c}{ Prison } & \multicolumn{2}{c}{ School } \\
\cline { 2 - 5 } & Nurse number & Nurse percent & Nurse number & Nurse percent \\
\hline $0-2$ & 444 & 99.8 & 56 & 100.0 \\
$2.1-10$ & 57 & 96.6 & 48 & 94.1 \\
$11-50$ & 73 & 79.3 & 240 & 95.2 \\
$51-100$ & 27 & 75.0 & 29 & 67.4 \\
$101-200$ & 72 & 49.3 & 21 & 30.0 \\
Total 0 - 100 & 601 & 95.1 & 373 & 92.8 \\
Total 0 - 200 & 673 & 86.5 & 394 & 83.5 \\
$2-3$ nurses & 42 & 6.2 & 74 & 18.8 \\
\hline
\end{tabular}

2-3 nurses indicate the number and percentage of ALMA that had more than one nurse plant.

Table 6. Nurse plant species for ALMA at two sites near Molepolole, Botswana.

\begin{tabular}{lcccc}
\hline \multirow{2}{*}{ Nurse species } & \multicolumn{2}{c}{ Prison site } & \multicolumn{2}{c}{ School site } \\
\cline { 2 - 5 } & Aloe number & Percentage & Aloe number & Percentage \\
\hline Acacia tortolis & 108 & 15.1 & 52 & 10.7 \\
Aloe marlothii & 117 & 16.4 & 105 & 21.6 \\
Boscia albitrunca & 3 & 0.4 & 0 & 0 \\
Boscia foetida subsp. rehmanniana & 207 & 29.0 & 0 & 0 \\
Combretum apiculatum & 18 & 2.5 & 11 & 2.3 \\
Combretum hereroense & 0 & 0 & 20 & 4.1 \\
Euclea undulata & 176 & 24.6 & 157 & 32.4 \\
Grewia bicolor & 1 & 0.1 & 4 & 0.8 \\
Grewia flava & 82 & 11.5 & 63 & 13.0 \\
Grewia monticola & 0 & 0 & 1 & 0.2 \\
Gymnospria senegalensis & 3 & 0.4 & 3 & 0.6 \\
Kleinia longiflora & 0 & 0 & 2 & 0.4 \\
Mimusops zeyheri & 0 & 0 & 3 & 0.6 \\
Mundulea sericea & 0 & 0 & 31 & 6.4 \\
Ozoroa paniculosa var. salicina & 0 & 0 & 4 & 0.8 \\
Peltophorum africanum & 0 & 0 & 13 & 2.7 \\
Rhigozum brevispinosum & 0 & 0 & 7 & 1.4 \\
Rhus leptodictya & 0 & 0 & 1 & 0.2 \\
Rhus pyroides & 0 & 0 & 2 & 0.4 \\
Ziziphus mucronata & 0 & 0 & 6 & 1.2 \\
Total & 715 & & 485 & \\
\hline
\end{tabular}

The total number of ALMA is greater than the total number with a nurse plant because at the Prison site, 42 ALMA had 2 or 3 nurse plants and at the School site, 74 ALMA had 2 or 3 nurse plants.

due to drought, herbivory and trampling. The Prison site population gives evidence for population decline with more individuals in the 101 to $200 \mathrm{~cm}$ size class than in the smaller size classes (except seedlings). This population should be monitored on a regular basis to determine if seedlings are able to recruit into larger size classes. It is possible that the rate of growth slows dramatically in taller ALMA and a larger number of individuals in the
101 to $200 \mathrm{~cm}$ size class is not indicative of decline. At the School site, if the 11 to $50 \mathrm{~cm}$ size class is ignored the size class with the greatest number of individuals is also 101 to $200 \mathrm{~cm}$. However, the School site appears more stable with a large number of individuals 11 to 50 $\mathrm{cm}$ tall that will presumably grow into larger size classes. The validity of the size-age relationship for ALMA is unknown, so long-term monitoring would be usefull in 
Table 7. Mean \pm standard deviation and range for characteristics of dead ALMA.

\begin{tabular}{lcccc}
\hline \multirow{2}{*}{ ALMA characteristic (cm) } & \multicolumn{2}{c}{ Prison } & \multicolumn{2}{c}{ School } \\
\cline { 2 - 5 } & Mean \pm sd & Range & Mean \pm sd & Range \\
\hline Height & $151 \pm 106$ & $10-342$ & $31 \pm 35$ & $8-200$ \\
Trunk diameter & $8.5 \pm 5.5$ & $1-20$ & $4.0 \pm 1.7$ & $1-10$ \\
Nearest neighbor & $74 \pm 74$ & $6-245$ & $50 \pm 64$ & $4-330$ \\
\hline
\end{tabular}

Thirteen dead ALMA were measured at the Prison site and 34 at the School site.

Table 8. Density of different size classes of ALMA $/ 100 \mathrm{~m}^{2}$ in 11 to $10 \mathrm{~m} \times 10 \mathrm{~m}$ plots and a $500 \times 2 \mathrm{~m}$ transect in each of two sites. Sites are located near Molepolole, Botswana.

\begin{tabular}{ccccccccc}
\hline \multirow{2}{*}{$\begin{array}{c}\text { Size class } \\
(\mathbf{c m})\end{array}$} & \multicolumn{9}{c}{ Density $/ \mathbf{1 0 0} \mathbf{~ m}^{\mathbf{2}}$} \\
\cline { 2 - 9 } & \multicolumn{3}{c}{ Plots } & \multicolumn{2}{c}{ Pransect } & \multicolumn{3}{c}{ School site } \\
\cline { 2 - 9 } & Total & Reproductive & Total & Reproductive & Total & Reproductive & Total & Reproductive \\
\hline $0-2$ & 40.5 & 0 & 4.0 & 0 & 5.1 & 0 & 3.8 & 0 \\
$2-10$ & 5.4 & 0 & 22.6 & 0 & 4.6 & 0 & 4.3 & 0 \\
$11-50$ & 8.4 & 0 & 8.4 & 0 & 22.9 & 0 & 15.9 & 0 \\
$51-100$ & 3.3 & 0 & 6.5 & 0 & 3.9 & 2.5 & 4.8 & 0 \\
$101-200$ & 13.3 & 1.3 & 16.0 & 1.6 & 6.4 & 2.4 & 3.1 & 0.2 \\
$201-400$ & 8.5 & 2.9 & 7.9 & 3.5 & 3.8 & 0.7 & 1.7 & 1.2 \\
$>400$ & 0.2 & 0.2 & 0 & 0 & 0.4 & 0.2 & 0.1 & 0.1 \\
Total & 79.4 & 4.4 & 65.4 & 5.1 & 47.1 & 5.6 & 33.7 & 1.5 \\
\hline
\end{tabular}

determining the nature of the size-age correlation for this species.

The relatively small number of dead individuals does not indicate a high rate of mortality, although the length of time that a dead large individual will persist on the landscape is unknown. Unlike Aloe dichotoma, for example, ALMA does not remain standing after death.

The size-age relationship has been useful in showing that other arborescent succulents are in decline. In arid South Africa, the population structure of three keystone arborescent succulents, two endemics (Aloe pillansii and Pachypodium namaquanum) and one widespread $(A$. dichotoma) species were surveyed (Midgley et al., 1997). All three had low recruitment with very few individuals $<0.5 \mathrm{~m}$ in height, and both Aloe species had high adult mortality. The absence of juveniles was postulated to be caused by poaching by humans and trampling and herbivory by goats and donkeys. Adult mortality was largely due to herbivory by baboons and porcupines. Another more recent range-wide examination of adult $A$. dichotoma found the species to be decreasing, apparently because of high mortality from heat stress related to climate change (Foden et al., 2007).

In a population of the rare $A$. pillansii, there were 75 live individuals. Of these, $44 \%$ were $<1 \mathrm{~m}$ in height, $4 \%$ were 1 to $3 \mathrm{~m}$, and $52 \%$ were $>3 \mathrm{~m}$. Since 1937, an average of $1.4 \%$ of the plants $>3 \mathrm{~m}$ in height had died annually.
Thus, at this rate, the remaining plants $>3 \mathrm{~m}$ in height will be dead in 71 years. Factors such as plant theft, animal damage and poor recruitment conditions during the first 80 years of the 20th century may be the cause of the small number of plants 1 to $3 \mathrm{~m}$. Over the last 10 years, rainfall has been above average thereby causing a high proportion of smaller individuals.

The authors surmised that because of the loss of six seedlings from the population in the last 5 years, probably due to grazing or theft, this population will not survive unless there is intervention (Duncan et al., 2006).

The significant correlations between a large number of plant characteristics (Table 2) indicates that measurement of a single basic attribute, such as height or leaf number, will be sufficient to gain information about the plant. The strong correlation between both height and leaf number and capsule production show that larger individuals have greater reproductive output. Symes and Nicolson (2008) also found a positive correlation between height and reproductive output in ALMA, both in terms of number of racemes and in the frequency of reproductive events. However, they found that shorter plants were damaged by baboons before fruit set could occur, which did not occur in this study.

The large number of capsules and seeds produced and the apparent seed viability attest to the lack of problems such as pollinator limitation at these two Molepolole sites. 
Other Aloe species have exhibited difficulties in seed production perhaps because of pollinator limitation (Stokes and Yeaton, 1995). In addition, the greenhouse germination percentages were high. There do not appear to be any scarification requirements for the seeds. Thus, greenhouse populations can be very easily established to replenish populations or start new ones.

The disturbances most likely to impact ALMA populations include wood cutting, which would remove nurse plants and also cause trampling and damage to nearby ALMA, collection of whole plants for landscaping, collection of leaves for medicinal purposes, and livestock impacts such as herbivory and trampling. The patchiness of the seedlings (Table 4) also shows the vulnerability of this species to impacts because trampling in a small area may eliminate a large percentage of the extant ALMA.

The Molepolole ALMA populations are of immense historic importance and are worthy of protection. It would be useful if a long-term monitoring program was instituted in both of the populations assessing basic parameters such as height and longevity. Land could be set aside for preservation, education, tourism and aesthetic purposes. If the populations are in decline, the ease with which the plants can be raised in a greenhouse would yield plenty of planting stock. In addition, it is likely that ALMA is a critical resource for a wide variety of insects and birds in Molepolole and preserving this resource would be another benefit of protection.

The Mokolodi population is currently protected by virtue of its location inside the Game Reserve. Mokolodi Game Reserve protects the habitat of white rhinos and many other wildlife species and the protection of the $A$. marlothii population there is a byproduct of the wildlife habitat preservation. The reasons for the complete lack of any individuals in the smaller size classes are unknown and are worthy of investigation. It may be that baboons or other herbivores are consuming the seedlings. The Mokolodi Nature Reserve was established in 1991 so it is possible but unlikely that juveniles were wiped out by cattle before the reserve was established and a new recruitment event is yet to occur. In any case, it is possible that this population may be in extreme decline and poised for a local extirpation.

\section{Conclusion}

This study showed that for ALMA at the two Molepolole populations, the most common size classes were small. However, there was a large number of ALMA in the 101 to $200 \mathrm{~cm}$ size class. Seedlings were patchily distributed and most ALMAs were found under nurse plants. Plant height and a variety of other plant attributes were strongly correlated, including being reproductive and number of capsules. Seed production and viability were high. Thus, the Molepolole populations appear relatively stable, whereas the Mokolodi population may be in decline due to a lack of smaller individuals.

\section{REFERENCES}

Campbell AC, Main M (2003). Guide to Greater Gaborone. The Botswana Society, Gaborone.

Drezner TD (2003). Saguaro (Carnegiea gigantea, Cactaceae) ageheight relationships and growth: the development of a general growth curve. Am. J. Bot. 90:911-914.

Drezner TD (2006). Regeneration of Carnegiea gigantea (Cactaceae) since 1850 in three populations in the northern Sonoran Desert. Acta Oecol. 29:178-186.

Duncan J, Hoffman T, Rohde R, Powell E, Hendricks H (2006). Longterm population changes in the Giant Quiver Tree, Aloe pillansii in the Richtersveld, South Africa. Plant Ecol. 185:73-84.

Foden W, Midgley GF, Hughes G, Bond WJ, Thuiller W, Hoffman MT, Kaleme P, Underhill LG, Rebelo A, Hannah I (2007). A changing climate is eroding the geographical range of the Namib Desert tree Aloe through population declines and dispersal lags. Divers. Distrib. 13:645-653.

Grace OM, Simmonds MSJ, Smith GF, Van Wyk AE (2008). Therapeutic uses of Aloe L. (Asphodelaceae) in southern Africa. J. Ethnopharmacol. 119:604-614.

Grace OM, Simmonds MSJ, Smith GF, Van Wyk AE (2009). Documented utility and biocultural value of Aloe L. (Asphodelaceae): a review. Econ. Bot. 63:167-176.

International Institute for Sustainable Development (IISD) (2011). Arid and semi-arid lands: Characteristics and importance. http://www.iisd.org/casl/asalprojectdetails/asal.htm. Accessed 15 May 2011.

Jordan PW, Nobel PS (1979). Infrequent Establishment of Seedlings of Agave deserti (Agavaceae) in the Northwestern Sonoran Desert. Am. J. Bot. 66:1079-1084.

Jordan PW, Nobel PS (1982). Height distribution of two species of cacti in relation to rainfall, seedling establishment and growth. Bot. Gaz. 143:511 -517.

Kew Royal Botanical Gardens (2011). Aloe marlothii (mountain aloe). http://www.kew.org/plants-fungi/Aloe-marlothii.htm. Accessed 10 June 2011

Midgley JJ, Cowling RM, Hendricks H, Desmet PG, Esler K, Rundel P (1997). Population ecology of tree succulents (Aloe and Pachypodium) in the arid western Cape: decline of a keystone species. Biodivers. Conserv. 6:869-876.

Newton LE (2001). Aloe. In: Eggli, U. (ed). CITES Aloe and Pachypodium Checklist. Royal Botanic Gardens, Kew; SukkulentenSammlung, Zurich.

Pierson EA, Turner RM (1998). An 85-Year Study of Saguaro (Carnegiea gigantea) Demography. Ecology 79:2676-2693.

Stokes CJ, Yeaton RI (1995). Population dynamics, pollination ecology and the significance of plant height in Aloe candelabrum. Afr. J. Ecol. 33:101-113.

Symes CT, Human H, Nicolson SW (2009). Appearances can be deceiving: Pollination in two sympatric winter-flowering Aloe species. S. Afr. J. Bot. 75:668-674.

Symes CT, Nicolson SW (2008). Production of copious dilute nectar in the bird-pollinated African succulent Aloe marlothii (Asphodelaceae). S. Afr. J. Bot. 74:598-605.

Titus JH (2004). A survey of saguaro at the northeastern elevational edge of their range. Desert Plants 20:11-16

Van Wyk BE, Smith G (2005). Guide to the Aloes of Southern Africa. Briza Publications, Pretoria.

World Weather Online (2011). Gaborone, Botswana Weather Averages. http://www.worldweatheronline.com/weather-

averages/Botswana/275462/Gaborone/275527/info.aspx. Accessed 15 May 2011. 